\title{
A Case of Coincidental Free Floating Thrombus in the Vertebral Artery in a Patient Presenting with an Anterior Circulation Stroke and Literature Review
}

\author{
Hosam Al-Jehani, MBBS, MSc, FRCSC ${ }^{1,2}$, May Adel Alhamid, MBBS, IAU-Neuro ${ }^{3}$, Yousef Alkhalaf, MD $^{4}$, \\ Faisal Alabbas, $\mathrm{MD}^{1}$ \\ ${ }^{1}$ Department of Neurosurgery, Interventional Radiology, King Fahad Hospital of The University, Imam Abdulrahman Bin Faisal, Dammam, \\ Saudi Arabia \\ ${ }^{2}$ Department of Neurology and Neursurgery, Montreal Neurological Institute and Hospital, McGill University, Montreal, QC, Canada \\ ${ }^{3}$ Department of Neurology, Interventional Radiology, King Fahad Hospital of The University, Imam Abdulrahman Bin Faisal, Dammam, Saudi \\ Arabia \\ ${ }^{4}$ Department of Medicine, Royal Commision Hospital, Jubail, Saudi Arabia
}

Free-floating thrombus (FFT) is a rare condition with unknown etiology as described by many case reports presented in previous literature. The patients usually present symptomatically while the other few patients remain asymptomatic and are usually discovered incidentally on computed tomography angiography (CTA). Most of the cases reported in the literature are of FFT in the internal carotid artery. We present a 59-year-old female as a case of FFT in the vertebral artery which was coincidently discovered on CTA in a patient initially presenting with an anterior circulation stroke. This case highlights the importance of early contrast-based vascular imaging in patients presenting with large vessel strokes that are cardioembolic in nature and the unique utilization of a direct aspiration first pass technique (ADAPT) for revascularization. Included herein an extensive review of the literature about the decision making in patients with FFT and a devised proposed practical approach to this entity.

Key Words: Free-floating thrombus; Vertebral artery; Middle cerebral artery; Acute ischemic stroke; Thrombectomy

\section{INTRODUCTION}

Free-floating thrombus (FFT) is a rare condition and has been infrequently reported in the literature. The first-ever FFT was reported with postmortem in 1905.' The exact etiopathogenesis of FFT remains unknown, although detached atherosclerotic plaque and hypercoagulable states could be considered as the likely causes. ${ }^{2}$ Many case-reports have reported the occurrence of FFT in the carotid artery, mostly the internal carotid artery (ICA). Such patients usually present with a neurological deficit as a consequence of completed stroke with fixed deficits, stroke-in-evolution, or transient ischemic attacks (TIAs). ${ }^{3}$ A few asymptomatic cases have also been reported. The diagnosis of an acute ischemic stroke is done initially with the help of plain computed tomography (CT) and magnetic resonance imaging (MRI). This is followed by CT angiogra-

\section{Correspondence to:} Hosam Al-Jehani, MBBS, MSc, FRCSC Department of Neurology and Neursurgery, Montreal Neurological Institute and Hospital, McGill University, c/o Luisa Birri, 3801 University St., Suite 109, Montreal, QC, H3A 2B4, Canada Tel: +1-514-398-1935

Fax: +1-514-398-2811

E-mail: hjehani@iau.edu.sa

Received: March 19, 2020

Revised: July 20, 2020 Accepted: July 21, 2020

Copyright $\odot 2020$ Korean Society of Interventional Neuroradiology This is an Open Access article distributed under the terms of the Creative Commons Attribution Non-Commercial License (http://creativecommons.org/licenses/by-nc/4.0) which permits unrestricted non-commercial use, distribution, and reproduction in any medium, provided the original work is properly cited.

pISSN 2093-9043 eISSN 2233-6273 
phy (CTA) for the confirmation of large vessel occlusion. ${ }^{4} \mathrm{FFT}$ on CTA is seen as an intra-luminal filling defect and can easily be differentiated from an atherosclerotic plaque. ${ }^{5}$ Hence, it is the preferred diagnostic choice in FFT. The available therapeutic management options for such cases are either interventional or medical therapy. ${ }^{6}$ A consensus on the optimal management strategy for FFT is not yet established. ${ }^{7}$ Bhatti et al. ${ }^{8}$ reported that the majority of cases (68\%) of FFT underwent surgical management and 30\% had medical management with main anticoagulants and antiplatelet therapy. The 30-day postoperative-management outcomes were almost the same in both types of intervention.

We describe a case in which a FFT was discovered coincidently in the vertebral artery in a patient presenting with an anterior circulation stroke. We aim to discuss the importance of early vascular imaging for stroke patients and our acute interventional strategy here. In addition, we conducted an extensive review of the literature about the decision making in patients with FFT and devised a proposed practical approach to this entity.

\section{CASE REPORT}

\section{Patient information \& diagnostic findings}

A 59-year-old right-handed Caucasian lady, known to have migraine with aura and type-2 diabetes mellitus presented to our emergency department center with dysarthria, left upper motor neuron facial weakness and left-sided hemiparesis affecting the upper limb more than the lower limb. The patient presented with signs of a right middle cerebral artery (MCA) stroke with an National Institute of Health Stroke Scale (NIHSS) of 10 and unfortunately was out of the window period for intravenous thrombolysis as it was a wake-up stroke and last seen well (LSW) was unknown. A MRI of the brain was obtained on an urgent basis which showed an established infarction in the anterior third of the right MCA territory secondary to the occlusion of the superior M2 branch of the right MCA (Fig. 1).

Upon further workup, CTA showed a filling defect in the right V4 segment of the right vertebral artery which was suspected of being a dissection or a FFT, with normal flow in the left vertebral artery and the basilar artery and its distal branches (Fig. 2).

The attending neurologist in the referring hospital discussed the case with our neurovascular on-call team and the patient was then transferred urgently to our hospital for emergent endovascular therapy (EVT).

\section{Intervention}

The patient was transferred to King Fahad hospital of

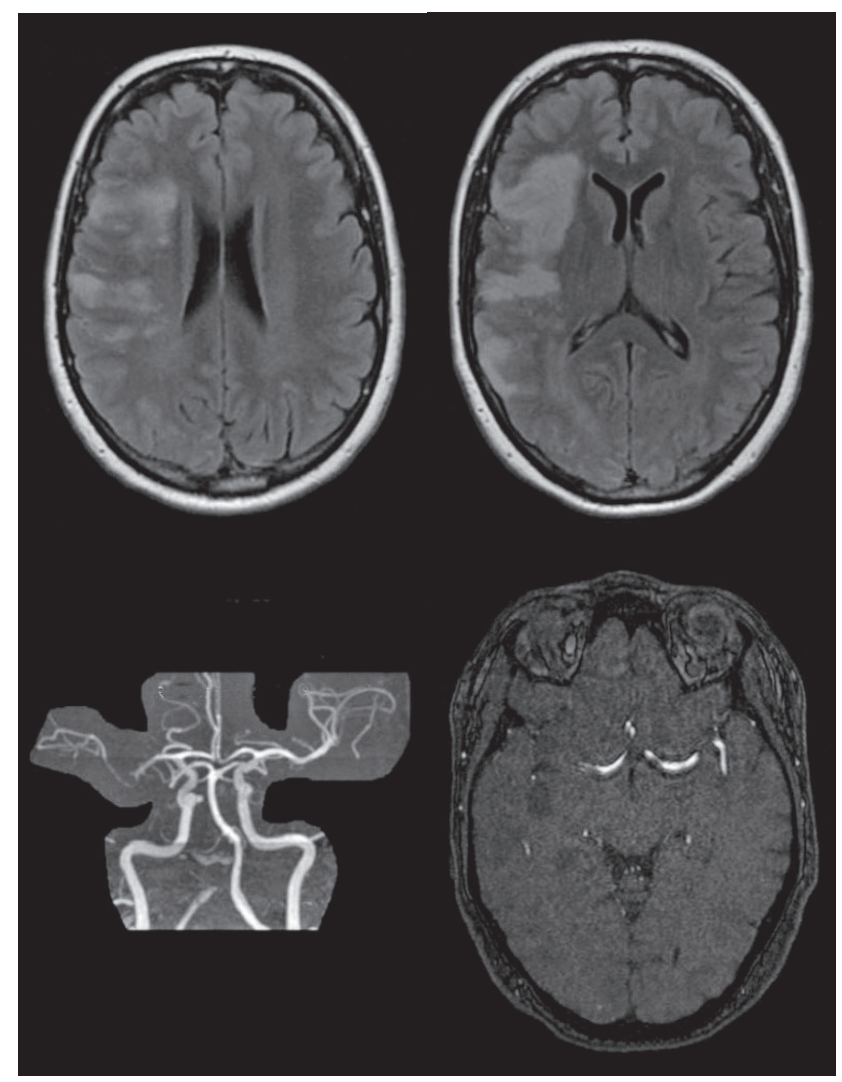

Fig. 1. Magnetic resonance imaging brain showing the sizable right middle cerebral artery (MCA) territory ischemic stroke on FLAIR imaging (upper panel). The magnetic resonance angiography shows the occlusion of the superior branch of the right MCA (lower panel).

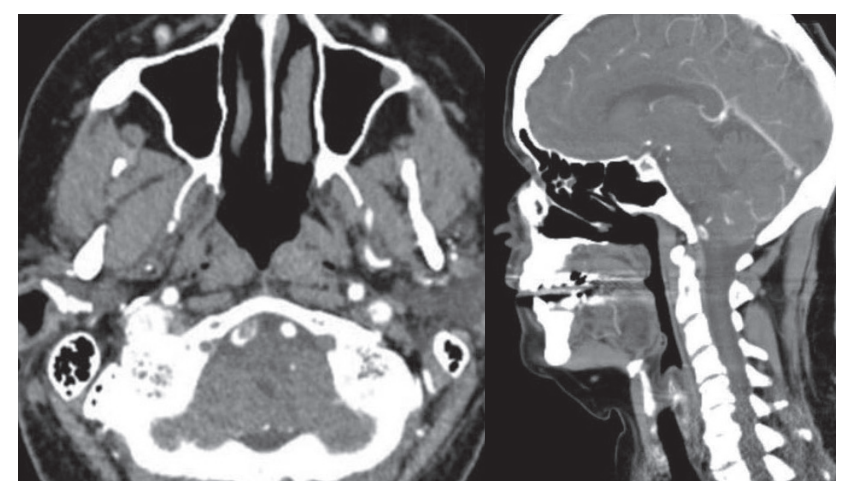

Fig. 2. Computed tomography angiography with axial and sagittal demonstration of the free-floating thrombus in the right vertebral artery at the junction of the $\mathrm{V} 3-4$ segment. $R$, right; $L$, left. 
the university the same night. An urgent angiogram was performed through a 5-F femoral sheath and a diagnostic catheter, under local anesthesia. The left ICA injection showed a normal flow into the MCA territory as well as the anterior cerebral artery (ACA) territory, with no cross flow to the right hemisphere. The right ICA injection showed the previously mentioned occlusion of the superior M2 branch with deficient collaterals to central MCA core territory. The left vertebral injection showed normal flow in its intracranial segment with no reflux into the right vertebral artery with normal flow into the basilar artery and its distal branches (Fig. 3A). The right vertebral artery was accessed just at its origin and a slow injection of contrast was administered in fear of dislodging any parts of the suspected thrombus. This injection confirmed the presence of the FFT in the V4 segment of the right vertebral artery with non-visualization of the right posterior-inferior cerebellar artery (PICA) or the distal flow into the basilar artery despite minimal filling of the contrast around the clot (Fig. 3B).

Using an exchange wire, The vertebral catheter was exchanged into a 5-F intermediate catheter (Sofia; Microvention, Aliso Viejo, CA, USA). The intermediate catheter, under road map guidance; was advanced with limited wire excursion into the area of the clot. This was followed by manual aspiration that yielded a multiple clot fragments (Fig. 3C). Post aspiration angiogram showed complete revascularization of the right vertebral artery with a slight delay in the right PICA with mild stenosis in the V3-4 junction (Fig. 3D). The patient tolerated the procedure well and remained stable neurologically.
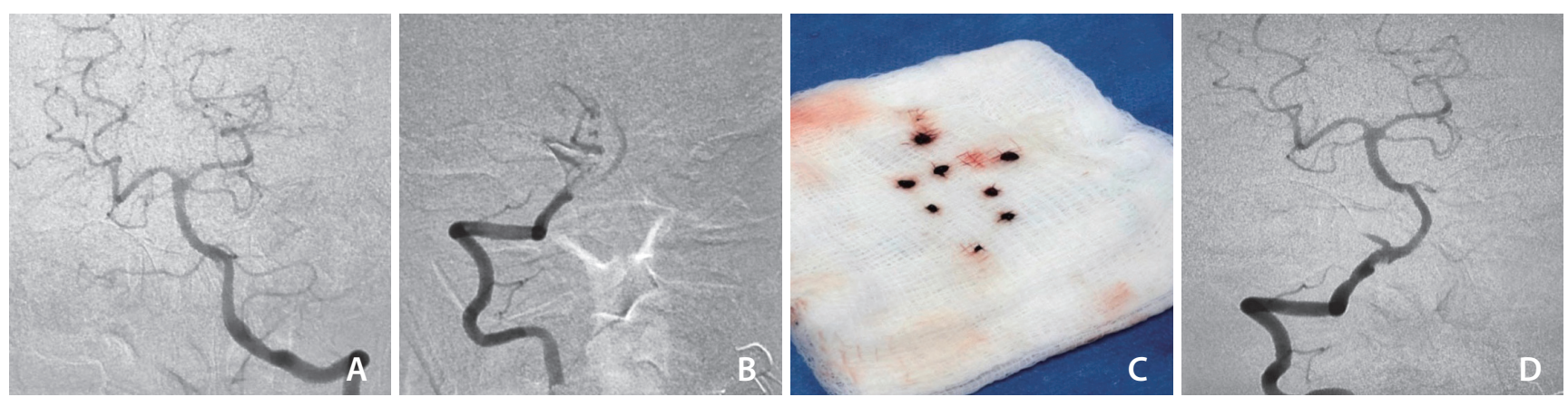

Fig. 3. Diagnostic and interventional angiogram. (A) Left vertebral angiographic run showing no cross flow into the right vertebral artery. (B) The right vertebral angiographic run showing the filling defect of the free-floating thrombus (FFT) with minimal contrast flow into the distal vertebral artery. (C) The aspirated fragments of the FFT. (D) Right vertebral angiographic run post contact aspiration showing no flow limitation in the vertebral artery with mild stenosis at the V3-4 junction with sluggish flow in the right posterior-inferior cerebellar artery. 


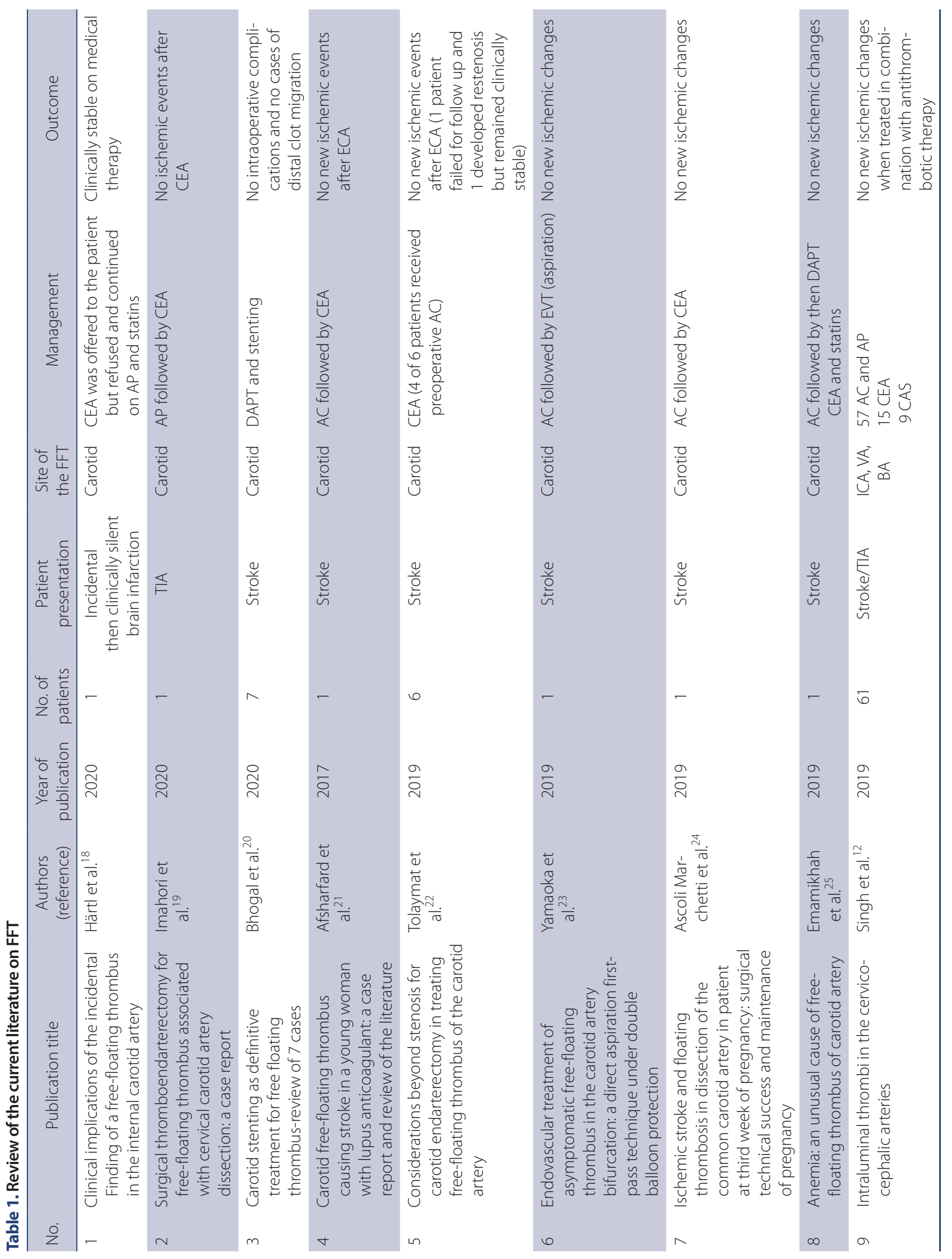




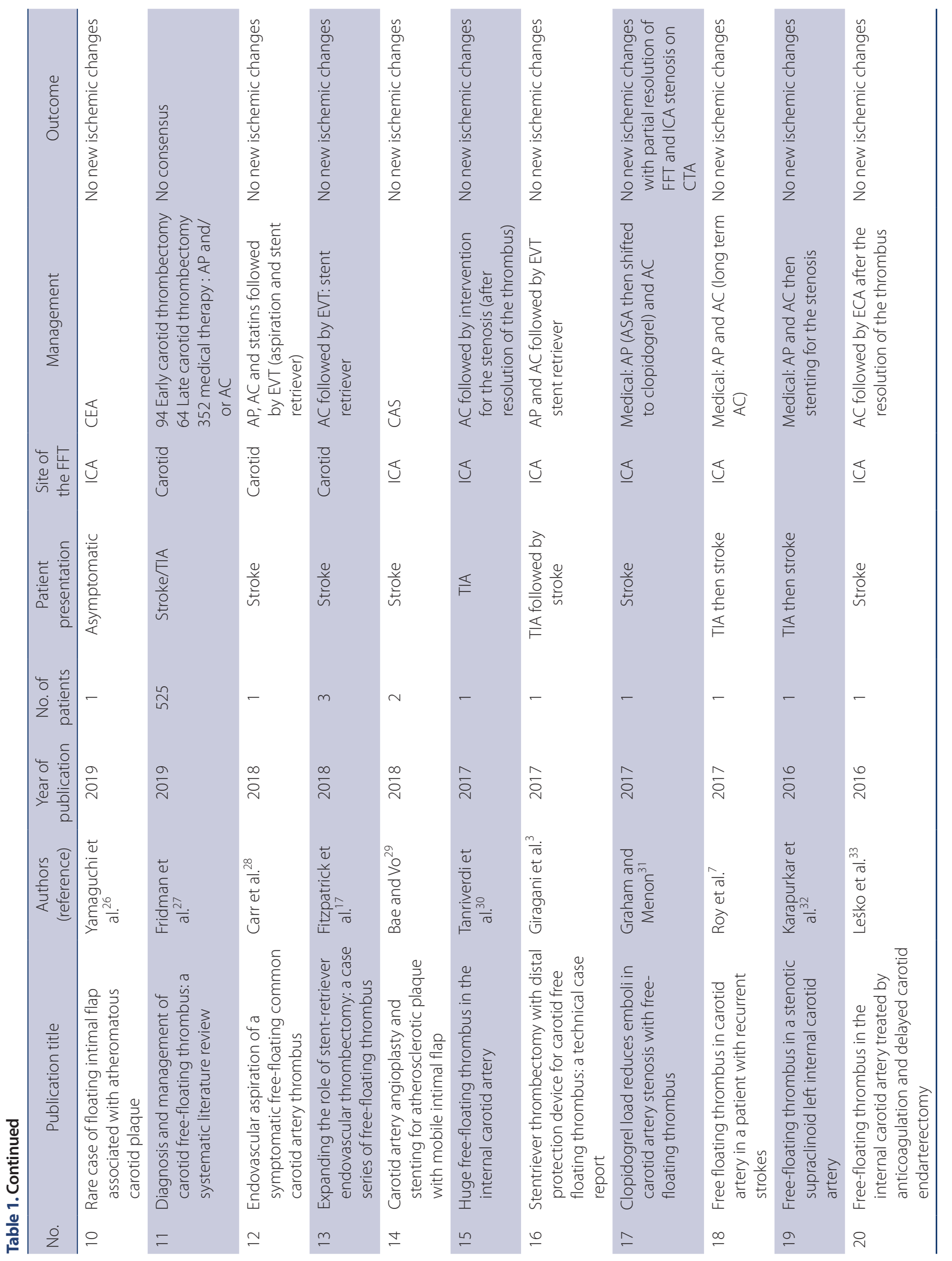




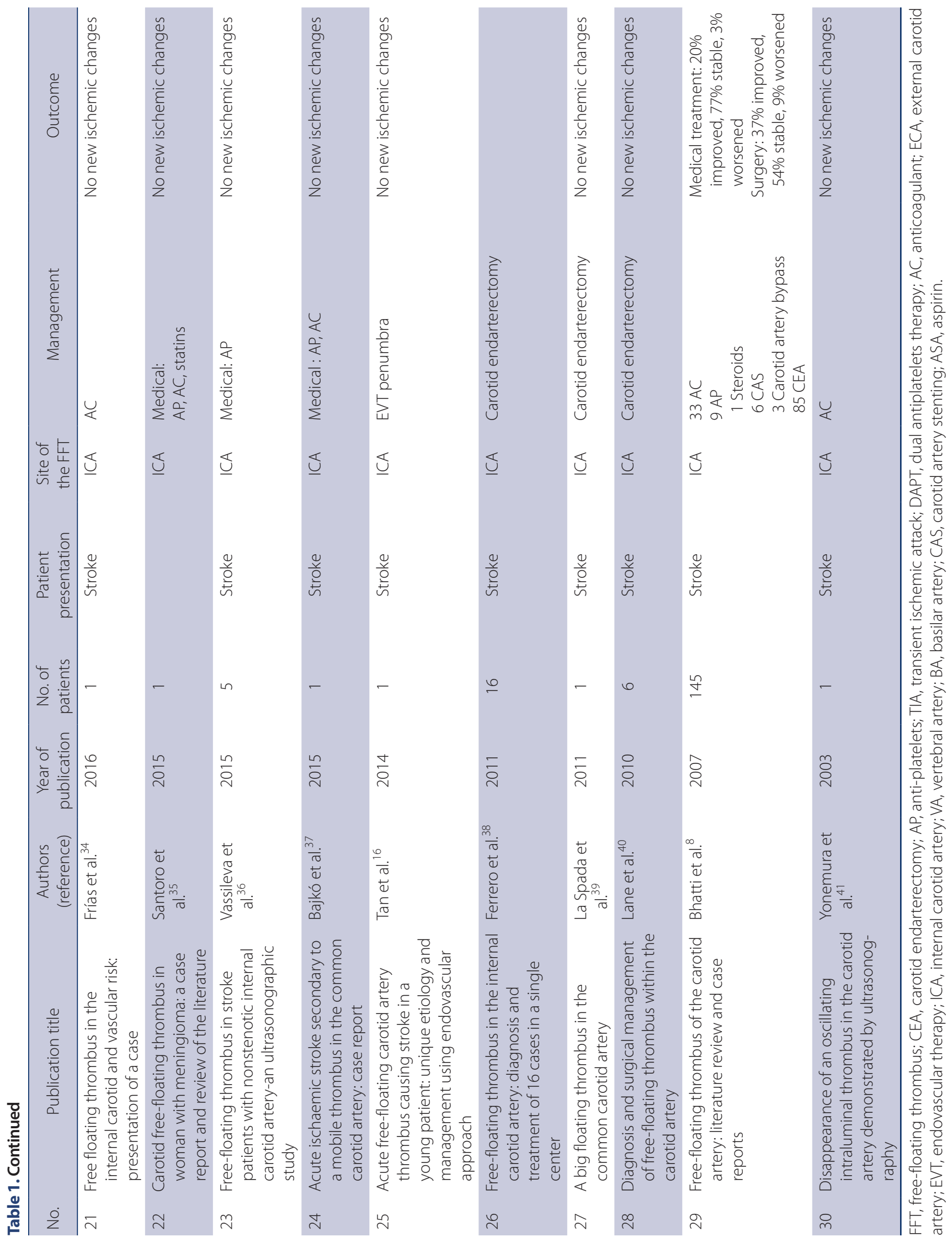


covered through transesophageal echocardiogram (TEE). In addition, she was found to have paroxysmal atrial fibrillation (AF). Given the presence of these 2 risk factors for cardioembolic strokes, the patient was started on anticoagulation in the form of vitamin $\mathrm{K}$ antagonist (VKA) warfarin for secondary stroke prevention. A follow-up echocardiogram and TEE were to be done in 3 months to assess the status of the left atrial appendage thrombus but unfortunately, the patient failed to follow up.

\section{DISCUSSION}

FFT has been reported in the literature in both the cervical carotid arteries followed by the vertebral arteries with almost all of them presenting symptomatically. ${ }^{8}$ These were also termed intraluminal thrombus (ILT), intraluminal clot and were referred to as the doughnut sign., ${ }^{9,10}$ Studies based on catheter angiography reported a prevalence of FFT ranging from $0.4 \%$ to $1.5 \%$ in patients with stroke or TIAs and with the recent utilization of CTA in those patients presenting acutely the prevalence has gone up to almost 3.2\%. ${ }^{9-12}$

In a recently published study, Singh et al. ${ }^{12}$ demonstrated that the most common location of FFT was extracranial ICA at $65.6 \%$ followed by extracranial vertebral artery at $11.2 \%$. Intracranial FFT was seen collectively in $18.0 \%$ of patients. The intracranial ICA and the basilar artery were each affected in $6.6 \%$ of patients followed by the vertebral artery affected in



Fig. 5. A proposed practical approach to free-floating thrombus (FFT). CEA, carotid endarterectomy; EVT, endovascular therapy. 
$3.3 \%$ of patients.

The most common cause associated with FFT is atherosclerotic disease of the affected vessel with either complicated plaque (ulcerated or fissured) with or without stenosis. Other possible associations include arterial dissections, cardioemoblic events, and hypercoagulable states. ${ }^{12}$

There still remains a debate about the ideal method of treating these patients whether it be medical treatment with the different types of antithrombotics versus EVT such as stenting, stent retrievers and/or a direct aspiration first pass technique (ADAPT). ${ }^{8,13}$

A retrospective study by Gülcü et al. ${ }^{14}$ emphasized the use of medical management for resolution of FFT with successful post-management outcome. ${ }^{13}$ This can be supported as an option in asymptomatic or stable patients with silent infarcts. In addition, this approach seems to be favored in the presence of non-flow limiting stenosis or dissection with the rapid resolution of the thrombus on serial imaging in the first 2 to 3 weeks of the event.

When managing patients with carotid artery dissection or those with a significant/complicated atherosclerotic plaque, there is a tendency to favor surgical thromboendarterectomy. This is thought to minimize vessel manipulation and allows for placing intimal tacking sutures which can prevent flap progression which reduces the risk of cerebral embolism. In the recent literature, there is a trend to utilize endovascular therapies for FFT. These can be offered either acutely or in a delayed manner mostly targeting residual stenosis. These options include clot contact aspiration with the ADAPT technique or stenting. ADAPT is a simple, efficient, and safe technique for revascularization of large vessel occlusion in patients with acute ischemic stroke..$^{15}$ It was found to have a favorable profile with proximal occlusion and when the culprit for the FFT is deemed inflammatory arteritis. ${ }^{16}$ If the artery is found to have a residual stenosis that is flow-limiting, we would advocate for stenting of the offending plaque in an expedited manner. These options lend themselves to debate when the offending vessel is in the anterior circulation. In contrast, the treatment options of posterior circulation vessels affected by FFT are limited to either medical therapy or endovascular means. There is no consensus of the management protocol for FFT. We summarized the existing literature on this entity in Table 1. 3,7,12,16-41 Although it is difficult to establish a consensus on a management approach for FFT, we devised as proposed practical approach to FFT in a decision tree presented in Fig. 5.
Our patient had symptoms primarily related to an acute ischemic MCA stroke. She did not manifest any symptoms related to posterior circulation, despite harboring a FFT in the vertebral artery, which was incidentally observed during imaging. This stresses the importance of CTA in detecting FFT especially in asymptomatic cases like ours.

To our knowledge, this represents the first case reported in the English literature of an asymptomatic FFT in the vertebral artery in a patient presenting with an MCA stroke. It is extremely fascinating that the FFT in this patient's right vertebral artery remained clinically silent, despite the lack of direct filling in the right PICA, which could have rendered her with defects if not a full-blown Wallenberg syndrome.

In our patient, we opted for EVT over medical therapy in fear of the risk of hemorrhagic transformation in the sizable ischemic MCA infarct. To that end we chose ADAPT as our first option of interventional management. From a technical stand point, this technique mitigated any wire or microcatheter manipulation that might have dislodged the clot into the basilar artery, which poses a significant risk of morbidity. We also used an almost wire-less advancement of the intermediate catheter especially beyond the V2-3 junction to avoid the same potential of inadvertent clot manipulation.

This case illustrates the importance of obtaining an early contrast-based vascular imaging in all patients affected with acute ischemic stroke to be able to visualize anterograde and retrograde flow in any given vessel. This would help in stratifying risks and needed interventions accordingly.

In conclusion, this is the first reported case of an asymptomatic FFT in the vertebral artery that was discovered coincidently in a patient presenting with an anterior circulation stroke. It highlights the importance of early acquisition of vascular imaging for all stroke patients and the timely utilization of EVT (ADAPT) as a safe and preferred method of acute revascularization in such cases.

\section{Fund}

None.

\section{Ethics Statement}

An informed consent was obtained from the patient for publication of this paper.

\section{Conflicts of Interest}

The authors have no conflicts to disclose. 


\section{Author Contributions}

Concept and design: HAJ and MAA. Analysis and interpretation: HAJ and MAA. Data collection: MAA and YA. Writing the article: MAA and HAJ. Critical revision of the article: HAJ, YA, and FA. Final approval of the article: HAJ, MAA, and FA. Statistical analysis: MAA. Obtained funding: none. Overall responsibility: HAJ.

\section{ORCID}

Hosam Al-Jehani: https://orcid.org/0000-0002-3830-9789

May Adel Alhamid: https://orcid.org/0000-0002-4521-1827

Faisal Albbas: https://orcid.org/0000-0003-4392-5233

\section{REFERENCES}

1. Chiari H. Uber das verhalten des teilungswinkels der carotis communis bei der endarteritis chronica deformans. Verh Dtsch Ges Pathol 1905;9:326-330 German.

2. Devuyst G, de Bray JM, Despland PA, Maeder P, Meuli R, Uské A, et al. Focal adherent thrombus in the common carotid artery: clinical, ultrasonographic, and pathogenic aspects in two cases. J Ultrasound Med 2000;19:707-711

3. Giragani S, Balani A, Agrawal V. Stentriever thrombectomy with distal protection device for carotid free floating thrombus: a technical case report. J Neurointerv Surg 2017;9:e33

4. Musuka TD, Wilton SB, Traboulsi M, Hill MD. Diagnosis and management of acute ischemic stroke: speed is critical. CMAJ 2015;187:887-893

5. Jaberi A, Lum C, Stefanski P, Thornhill R, lancu D, Petrcich W, et al. Computed tomography angiography intraluminal filling defect is predictive of internal carotid artery free-floating thrombus. Neuroradiology 2014;56:15-23

6. Combe J, Poinsard P, Besancenot J, Camelot G, Cattin F, Bonneville JF, et al. Free-floating thrombus of the extracranial internal carotid artery. Ann Vasc Surg 1990;4:558-562

7. Roy M, Roy AK, DeSanto JR, Abdelsalam M. Free floating thrombus in carotid artery in a patient with recurrent strokes. Case Rep Med 2017;2017:4932567

8. Bhatti AF, Leon LR Jr, Labropoulos N, Rubinas TL, Rodriguez H, Kalman PG, et al. Free-floating thrombus of the carotid artery: literature review and case reports. J Vasc Surg 2007;45:199-205

9. Biller J, Adams HP Jr, Boarini D, Godersky JC, Smoker WR, Kongable G. Intraluminal clot of the carotid artery. A clinical-angiographic correlation of nine patients and literature review. Surg Neurol 1986;25:467-477
10. Menon BK, Singh J, Al-Khataami A, Demchuk AM, Goyal M; Calgary CTA Study Group. The donut sign on CT angiography: an indicator of reversible intraluminal carotid thrombus? Neuroradiology 2010;52:1055-1056

11. Puetz V, Dzialowski I, Coutts SB, Hill MD, Krol A, O'Reilly C, et al.; Calgary CTA Study Group. Frequency and clinical course of stroke and transient ischemic attack patients with intracranial nonocclusive thrombus on computed tomographic angiography. Stroke 2009;40:193-199

12. Singh RJ, Chakraborty D, Dey S, Ganesh A, Al Sultan AS, Eesa $M$, et al. Intraluminal thrombi in the cervico-cephalic arteries. Stroke 2019;50:357-364

13. Halliday A, Mansfield A, Marro J, Peto C, Peto R, Potter J, et al.; MRC Asymptomatic Carotid Surgery Trial (ACST) Collaborative Group. Prevention of disabling and fatal strokes by successful carotid endarterectomy in patients without recent neurological symptoms: randomised controlled trial. Lancet 2004;363:14911502

14. Gülcü A, Gezer NS, Men S, Öz D, Yaka E, Öztürk V. Management of free-floating thrombus within the arcus aorta and supra-aortic arteries. Clin Neurol Neurosurg 2014;125:198-206

15. Turk AS, Frei D, Fiorella D, Mocco J, Baxter B, Siddiqui A, et al. ADAPT FAST study: a direct aspiration first pass technique for acute stroke thrombectomy. J Neurointerv Surg 2018;10(Suppl 1):i4-i7

16. Tan AP, Taneja M, Seah BH, Leong HN, Venketasubramanian N. Acute free-floating carotid artery thrombus causing stroke in a young patient: unique etiology and management using endovascular approach. J Stroke Cerebrovasc Dis 2014;23:e437-e439

17. Fitzpatrick N, Motyer R, Gibney B, Duffy S, Murphy S, O'Brien P, et al. Expanding the role of stent-retriever endovascular thrombectomy: a case series of free-floating thrombus. J Neurointerv Surg 2018;10:1164-1167

18. Härtl J, Mühlau M, Pernpeintner V, Seifert C, Kreiser K, Schäffer $C$, et al. Clinical implications of the incidental finding of a free-floating thrombus in the internal carotid artery. [published online ahead of print Jan 19, 2020] J Clin Ultrasound 2020

19. Imahori T, Tanaka K, Arai A, Kohmura E. Surgical thromboendarterectomy for free-floating thrombus associated with cervical carotid artery dissection: a case report. [published online ahead of print May 18, 2020] Ann Vasc Surg 2020

20. Bhogal P, AlMatter M, Aguilar Pérez M, Bäzner H, Henkes H, Hellstern V. Carotid stenting as definitive treatment for free floating thrombus-review of 7 cases. [published online ahead of print Mar 27 2020] Clin Neuroradio/ 2020

21. Afsharfard A, Gholizadeh B, Abdolalian Y, Hosseini SM. Carotid 


\section{Al-Jehani $\mathrm{H}$ et al. Coincidental Free-Floating Vertebral Thrombus with MCA Stroke}

free-floating thrombus causing stroke in a young woman with lupus anticoagulant: a case report and review of the literature. Int J Surg Case Rep 2017;33:35-37

22. Tolaymat B, Irizarry K, Reif M, Drucker CB, Aicher BO, Sarkar R, et al. Considerations beyond stenosis for carotid endarterectomy in treating free-floating thrombus of the carotid artery. Ann Vasc Surg 2019;60:221-228

23. Yamaoka A, Miyata K, lihoshi S, Mikuni N. Endovascular treatment of asymptomatic free-floating thrombus in the carotid artery bifurcation: a direct aspiration first-pass technique under double balloon protection. BMJ Case Rep 2019;12:e230295

24. Ascoli Marchetti A, Diomedi M, Ascoli Marchetti S, Piccione E, Ippoliti A. Ischemic stroke and floating thrombosis in dissection of the common carotid artery in patient at third week of pregnancy: surgical technical success and maintenance of pregnancy. SAGE Open Med Case Rep 2019;7:2050313X19831117

25. Emamikhah M, Yazdi N, Mohebi N, Eslami M, Moghaddasi M. Anemia: an unusual cause of free-floating thrombus of carotid artery. Iran J Neurol 2019;18:87-89

26. Yamaguchi S, Hamabe J, Yamashita A, Irie J, Yagi N, Suyama K Rare case of floating intimal flap associated with atheromatous carotid plaque. World Neurosurg 2019;122:98-101

27. Fridman S, Lownie SP, Mandzia J. Diagnosis and management of carotid free-floating thrombus: a systematic literature review. Int J Stroke 2019;14:247-256

28. Carr K, Tew D, Becerra L, Siddall K, Dubensky L, Serulle Y. Endovascular aspiration of a symptomatic free-floating common carotid artery thrombus. Neuroradiology 2018;60:1103-1107

29. Bae E, Vo TD. Carotid artery angioplasty and stenting for atherosclerotic plaque with mobile intimal flap. Ann Vasc Surg 2018:49:310.e1-310.e3

30. Tanriverdi $U$, Kizilkilic $O$, Ince B. Huge free-floating thrombus in the internal carotid artery. J Stroke Cerebrovasc Dis 2017;26:30293030

31. Graham BR, Menon BK. Clopidogrel load reduces emboli in carotid artery stenosis with free-floating thrombus. Can J Neurol

\section{Sci 2017:44:594-596}

32. Karapurkar AP, Singh $R$, Teelala SM, Lalla R. Free-floating thrombus in a stenotic supraclinoid left internal carotid artery. BMJ Case Rep 2016;2016:bcr2015213067

33. Leško MIM, Guňka I, Lojík M, Krajičková D. [Free-floating thrombus in the internal carotid artery treated by anticoagulation and delayed carotid endarterectomy]. Rozhl Chir 2016;95:325328 Czech.

34. Frías Vargas M, Tavera Santos E, Carrasco Carrasco E, López Uriarte B. [Free floating thrombus in the internal carotid and vascular risk: Presentation of a case]. Semergen 2016;42:274-276 Spanish

35. Santoro L, Schinzari F, Di Veronica A, Cardillo C, Santoliquido A. Carotid free-floating thrombus in woman with meningioma: a case report and review of the literature. Eur Rev Med Pharmacol Sci 2015;19:1442-1445

36. Vassileva E, Daskalov M, Stamenova P. Free-floating thrombus in stroke patients with nonstenotic internal carotid artery-an ultrasonographic study. J Clin Ultrasound 2015;43:34-38

37. Bajkó Z, Maier S, Rusu S, Moțățăianu A. Acute ischaemic stroke secondary to a mobile thrombus in the common carotid artery: case report. J Crit Care Med (Targu Mures) 2015;1:68-70

38. Ferrero E, Ferri M, Viazzo A, Labate C, Pecchio A, Berardi G, et al. Free-floating thrombus in the internal carotid artery: diagnosis and treatment of 16 cases in a single center. Ann Vasc Surg 2011;25:805-812

39. La Spada M, Stilo F, Barillà D, Spinelli F. A big floating thrombus in the common carotid artery. J Cardiovasc Med (Hagerstown) 2011;12:819-820

40. Lane TR, Shalhoub J, Perera R, Mehta A, Ellis MR, Sandison A, et al. Diagnosis and surgical management of free-floating thrombus within the carotid artery. Vasc Endovascular Surg 2010:44:586-593

41. Yonemura K, Kimura K, Yasaka M, Minematsu K. Disappearance of an oscillating intraluminal thrombus in the carotid artery demonstrated by ultrasonography. Intern Med 2003;42:746-749 